\title{
What Might Affect the Acceptance Rate for Transgender People of Color? A Case Study in the United States
}

\author{
Yunlai Hong ${ }^{1 *}$ \\ ${ }^{1}$ Westtown School, West Chester, PA, USA \\ *Corresponding author. Email: cassie.hong@westtown.edu
}

\begin{abstract}
Transgender people of color are a minority experiencing the intersectionality of race and gender. Numerous crises and discriminations exist in their daily life, whereas little research is conducted to provide insights and solutions. To raise public awareness towards gender minorities in the diverse American society, this study explores three factors for the social acceptance rate in the United States for transgender people of color: Age, Education, and Socioeconomic Status. A mixed-method of quantitative questionnaires and qualitative interviews are utilized as the research methodology. The main findings of this study are: 1) A progressive relationship exists among these three factors; education is the direct factor, while age and socioeconomic status are two parallel sub-factors; 2) In the order of importance, the three factors are listed from a high to low sequence: education, age, and socioeconomic status; 3 ) For one question I brought up the thought for all-gender bathrooms instead of a binary male and female bathroom; thoughts on bathroom crisis are diverse, while majority supports all-gender bathrooms; 4) Gender education lacks in both schools and family. Based on these findings, some possible solutions for teachers, educational institutions, and transgender people of color are considered. As the few previous related studies mainly focus on people within the group, this paper also provides a new general social perspective on transgender people of color. To implement these potential solutions, much research is needed to further illustrate the phenomenon.
\end{abstract}

Keywords: Gender Equity, Transgender People, People of Color, Age, Education, Socioeconomic status, Bathroom Crisis

\section{INTRODUCTION}

Gender identity is a social structure affecting from large scale (e.g., national culture and organizations) to small ranges (e.g., workplace, family interactions, and individual cognition). In the 21 st century, gender inequality is still an urgent crisis faced by gender minorities in the contemporary United States [1]. Inequalities between males and females have been discussed and researched to a large extent in the past few decades [2]. Nonetheless, regardless of the racial and gender diversity in the United States, few studies have been conducted regarding transgender people of color. While, discriminations against the group exist in various aspects of society. Therefore, this research would use a case study in the United States to explore the determinants of social acceptance rate for transgender people of color, aiming at this specific minority group in terms of both race and gender. Due to the relatively small sample size, the case study may not be capable of representing the whole population in American society. Compared with previous studies, which focus on people inside the minority group, the study contributes a broader and general public perspective for studies regarding transgender people of color, which can inspire educational institutions, teachers, and transgender people of color themselves. Aiming at three determinants (age, education, socioeconomic status), the study also provides insights for further solutions and research.

\section{LITERATURE REVIEW}

\subsection{Concept and Existing Crisis}

\subsubsection{What is Intersectionality?}

Intersectionality brings up the innovative research method of thinking in multidimensionality, acknowledging the multiple aspects and nature of social structure and life [3]. Proposed by Kimberlé Williams Crenshaw, this concept has been broadly utilized in 
numerous research fields, including gender and women studies [4]. In this study, intersectionality indicates interrelationships between race and gender identity, which creates a multidimensional insight of social life among transgender people of color in the United States.

\subsubsection{Who are transgender people of color?}

As demonstrated in figure 1, "Transgender" is an umbrella term utilized for people whose gender identity mismatches their biological sex.

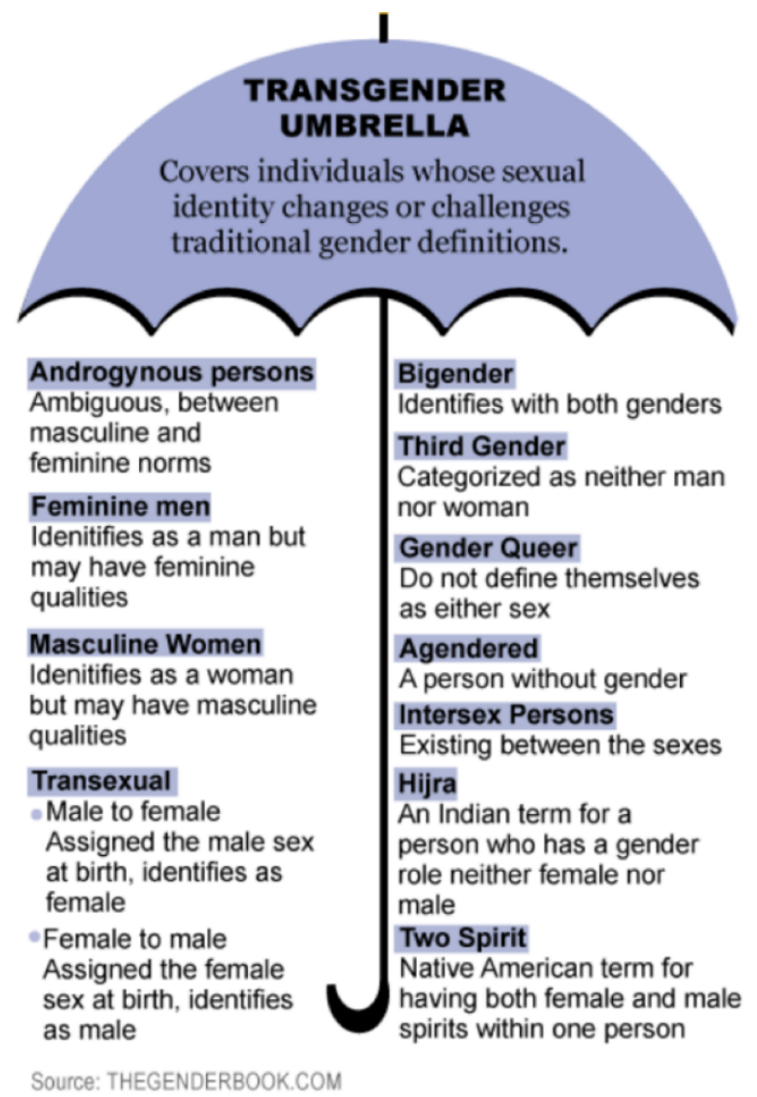

Figure 1 The categories and Definition of Transgender People [5]

Common misunderstandings about the concept of binary gender identity would cause a lack of confidence and sense of belonging in transgender and non-binary people [6]. On the other hand, "cisgender" refers to people whose gender identity corresponds with their biological sex. Sex is a medical term used to refer to biological sex, and it is determined by chromosomes, hormones, and genitalia. Male, female, and intersex are categories of sex. Gender identity refers to a person's mental and internal recognition of gender. There are numerous gender identities, including men, women, transgender people, genderqueer, gender fluid, etc. [7]. As an umbrella term, transgender people can be MTF (biologically male transformed to female), FTM (biologically female transformed to male), and nonbinary transgender people. Gender identity is not a binary definition. The concept of gender spectrum is used to clarify the "umbrella" property for gender identities. Transgender people of color are a marginalized minority in American society, experiencing interconnected difficulties for being marginalized in terms of races and genders.

\subsubsection{Existing Crisis}

As a racial and gender minority, transgender people of color encounter crises existing in American society. From the aspect of the workplace, Davidson (2016) finds that the unemployment rates for transgender people experience are twice as high as the rate for cisgender people. Transgender people of color, particularly African American transgender people, reflect worse employment results than white transgender people [7]. Verbal harassment, gender-specific dress codes, and the impossibility to get official identity on legal documents all contribute to less satisfying workplace experiences received by transgender people of color. Some transgender people of color may choose not to reveal their gender identity in the workplace. Bathrooms are a common place where verbal or even physical attacks towards transgender people occur. Mentally, transgender people of color would experience gender dysphoria, which refers to feelings of distress due to the mismatch of the biological sex and gender identity [7]. Gender dysphoria replaces its previous professional name, Gender Identity Disorder (GID) [8]. Women of color normally receive less income than white women, and women usually face burnout and difficulties in balancing work and home [9]. Even though the homicide rate for transgender people is less than the rate for cisgender people, the homicide rate for young Hispanic and Black transgender women is much higher than for cisgender women [10].

Besides workplaces, health is another essential issue faced by transgender people of color, even though the attitude towards transgender people has been shifting to a more open one [11]. Due to discriminations, policies, employment, and ignorance, transgender and gender nonconforming adults encounter barriers to health care, leading to severe social inequalities and results [12]. 40\% of respondents in a survey of Colorado report delays in medical care because of cost, inadequate insurance, and discrimination [13]. People of color are more likely to report a stigma on their physical and mental health.

\subsection{Factors}

The intersectionality that transgender people of color own represents their double minority status. Except for their gender and racial identity, other factors such as stable marriage, more wealth, younger age, and higher educational background also contribute to better physical and mental health [14]. 
Age, socioeconomic status, and educational background are three of the significant determinants in the living quality of transgender people of color in KatzWise et al.'s (2016) research. Transgender people of color with lower income and lower education report more possibility of self-harm. Self-identified transgender people of color with older age, a lower income, and a lower educational background are more likely to attempt suicide. Finally, older transgender individuals of Hispanic or multiracial identity with a lower income and lower education reflect more possibility on depression diagnosis [15].

\subsection{Research Gap}

The United States has been shifting to a more inclusive society for gender minorities in recent decades. Yet, most of the research in gender studies focuses on women and LGBTQ+ (Lesbian, Gay, Bisexual, Transgender, Queer/questioning, etc.) people experience as a whole. There is a lack of research on the intersectionality between race and gender. Besides, most of the research on transgender people is related to HIV infection, indicating that transgender women are more likely to be infected than transgender men or non-binary transgender people [16]. Finally, participants in a large number of the research are self-identified transgender people, so the results are mainly based on subjective perspectives from transgender people or transgender people of color. There is little research in discovering the social acceptance rate or social attitudes towards transgender people of color. Voices from people outside this marginalized group are scarce. Hence, this study will invite people with diverse personal identities, using a mixed-method of a quantitative questionnaire, qualitative personal interview, and thematic analysis to study the determinants of social acceptance rate in the United States for transgender people of color.

\subsection{Hypothesis}

There is a lack of data on the social acceptance rate in the United States of transgender people of color. Nonetheless, prior research and studies associated with transgender people in the United States or people of color in the United States reflect a worse living experience for those marginalized groups. Transgender people or people of color may have already encountered inequalities and discriminations in the workplace, bathrooms, the aspect of mental and physical health, etc. In numerous situations in life, transgender people of color may suffer from the intersectionality of both their racial and gender identity. This study explores the importance of certain determinants of social acceptance rate in the United States for transgender people of color.
Hypothesis 1: Younger generations in the United States would have a higher acceptance rate towards transgender people of color.

Hypothesis 2: People who come from a higher socioeconomic status in the United States would have a higher acceptance rate towards transgender people of color.

Hypothesis 3: People in the United States with higher education would have a higher acceptance rate towards transgender people of color.

\section{RESEARCH METHODS}

The purpose of this study is to explore the influential factors that affect the social acceptance rate in the United States for transgender people of color. A mixed-method of both quantitative and qualitative research methods will be utilized.

Being a case study in the United States, this study requires all the participants to have living experience in the United States for at least one year to accurately measure research results. 42 participants fill out the questionnaire, and 7 personal interviews are conducted.

The first part of the research methodology is an anonymous quantitative questionnaire. The questionnaire is spread out through the platform google form for convenience and familiarity for participants in the United States. The questionnaire contains basic personal information such as gender identity, age, socioeconomic status, and educational background; it also involves questions of likely scales and short answers for the participants to express their thoughts and personal anecdotes. The total questionnaire would take approximately 10 minutes to be completed.

Based on the quantitative questionnaire results, 7 participants were invited to conduct a personal interview with the research via Zoom due to the pandemic and difficulties in travelling. The interviewee will be asked to indicate their personal information (e.g., gender, age, race, educational background, and socioeconomic class) and answer 5 open-ended questions. The interview will last for about 20 minutes per person.

The consent is received when the participants did the questionnaire as the last question asks for their willingness to participate in further interviews. In the consent form, it is also mentioned that the interview will be fully recorded for further transcription and data analysis purposes, while the personal information and the recording will not be released to anyone other than the researcher. Pseudonyms will be used throughout the academic paper. In the data analysis part for qualitative personal interviews, thematic analysis, a common way to analyze qualitative data, will be used. A few similar or same themes will be selected out from various interviews 
and quotes with further explanations and analysis (Mojtaba et al., 2013).

\section{RESULTS AND DISCUSSIONS}

This section analyzes the related questions and results for each hypothesis to prove and discuss the previous three hypotheses. It follows the order of the three hypotheses, proving whether they are correct or wrong. The last part lists some extra findings in both the questionnaire and personal interviews.

\section{In your opinion, how influential is your age on the understanding of transgender people of color? 42 responses}

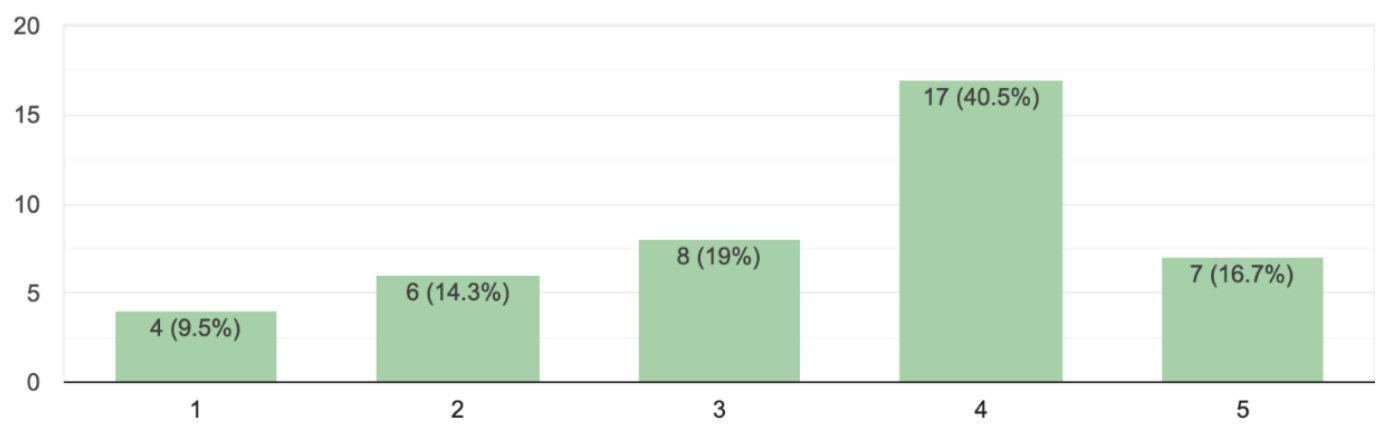

Figure 2 Participants' Answer on the Importance of Age

Hypothesis 1 is: Younger generations in the United States would have a higher acceptance rate towards transgender people of color. In the questionnaire, shown in figure $2,57.2 \%$ of 42 participants believe that age is an important or decisive factor in the social acceptance rate for transgender people of color. On the other hand, only $9.4 \%$ of participants consider age as an irrelevant factor in the social acceptance rate in the United States of transgender people of color. The majority of the participants are from the age between 15 to 20 , and they are more comfortable developing a more intimate relationship with transgender people of color, selecting mainly 4 and 5 in the related likely scale question. On the other hand, people above the age of 35 tend to have lower acceptance rates as almost all of them pick in the range from 1 to 3 for the same likely scale question, except for one participant who holds a Ph.D. degree and is from the upper-middle class.

\subsection{Hypothesis 1}

Based on this study, younger participants also know more transgender people of color than people from older generations, usually through schools and classes. Also, people largely favor having conversations regarding transgender people of color with their peers rather than parents or people from other generations. 28 out of 42 participants choose to talk with their peers, while other options (parents, faculty members, etc.) receive less than 10 votes on average. $31 \%$ of the participants do not hold conversations about transgender people of color at all. $45.2 \%$ of the participants do not have conversations with their parents, whereas $19 \%$ do not hold discussions with their peers. Figure 3 and figure 4 show that $66.7 \%$ of participants hold the same opinions as their peers, while only $21.4 \%$ share the same perspective as parents.

\section{Do you hold the same opinions on transgender people of color as your parents? 42 responses}

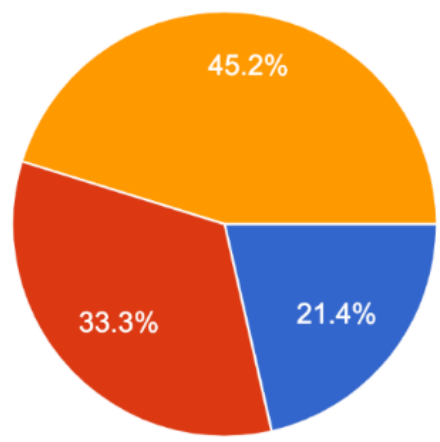

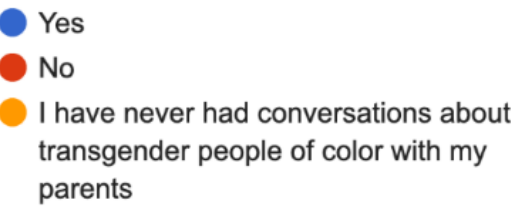
parents

Figure 3 Opinions on Transgender People of Color in Comparison to Parents 


\section{Do you hold the same opinions on transgender people of color as your peers?}

42 responses

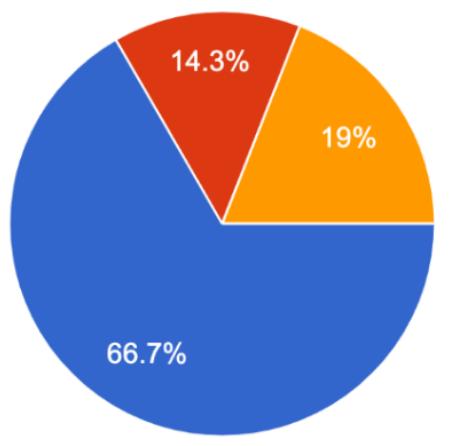

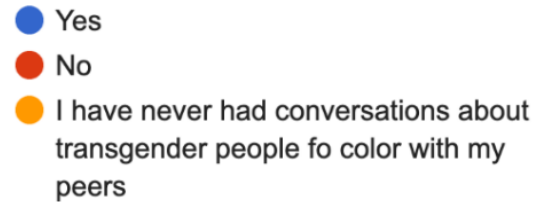

peers

Figure 4 Opinions on Transgender People of Color in Comparison to Peers

In the qualitative personal interviews, 4 out of 7 state that age is influential in people's understanding and acceptance of transgender people of color. Participants in the age range from 15 to 20 years old hold similar and positive opinions about transgender people of color. All of the younger participants mention the concept of intersectionality between race and gender, while older interviewees express difficulties getting used to the "new gender identity". One female participant in her seventies expresses the difficulties for her in the interview and people in the same age as her understanding the concept of "transgender".

"There was no transgender or genderqueer back in the days I was in college. There was even little about women's studies. When the concept of transgender got more and more prevalent in recent years, it is not easy for us to adapt to it. People my age started to question 'What is this?' Age is a big factor."

Nonetheless, not all the evidence supports hypothesis 1. The questionnaire also shows that $23.8 \%$ of participants consider age as an unimportant factor. Additionally, the number of gender studies classes that the participants have taken has no relationship with age. Therefore, in general, age is a significant factor in the social acceptance rate in the United States for transgender people of color. Yet, it is not a decisive determinant compared to education as some voices express the unimportance of age.

\subsection{Hypothesis 2}

Hypothesis 2 is: People who come from a higher socioeconomic status in the United States would have a higher acceptance rate towards transgender people of color. Illustrated in figure 5 , only $23.8 \%$ of 42 participants in the questionnaire view socioeconomic class as an essential determinant of social acceptance rate towards transgender people of color, with $2.4 \%$ people deeming socioeconomic class as the decisive factor. Evidence shows that socioeconomic status is relatively unimportant in determining people's rate of acceptance toward this minority group. $95.2 \%$ of the participants are from the middle, upper-middle, or upper class, while $42.9 \%$ do not personally know transgender people of color, as shown in figure 6.

\section{In your opinion, how influential is your socioeconomics status on the understanding of transgender people of color? \\ 42 responses}

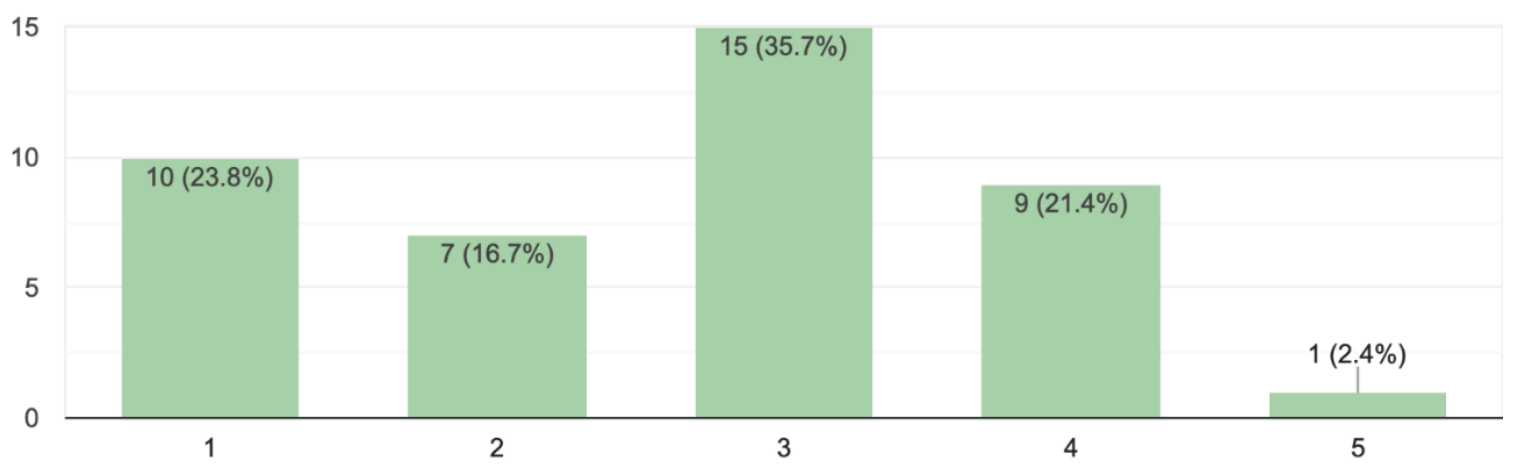

Figure 5 Participants' Answer on the Importance of Socioeconomic Status 


\section{How often to you talk, interact or meet with a transgender people of color?}
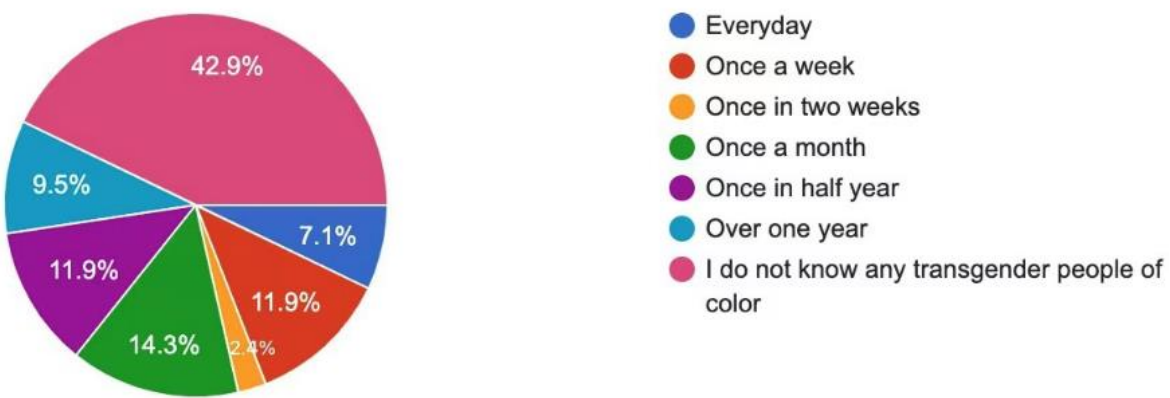

Figure 6 The Frequency of Conversation with Transgender People of Color

In personal interviews, all the participants are from classes higher than the middle class. Some of them feel privileged due to their racial and gender identity as well. Based on the information provided, all of them report a racially diverse friend group but usually less gender or socioeconomically diverse, which indicates the lack of effort in the society to collaborate in terms of gender and socioeconomic status. Participants who are part of the LGBTQ+ community tend to have more conversations related to transgender people of color in some organizations, such as PRIDE (Promote Respect, Inclusion, and Dignity for Everyone, Personal Rights in Defense and Education). However, for "outsiders" in the situation, conversations regarding this minority group seldom or never happens in their daily life. One bisexual female shares her experience in PRIDE, an organization that supports LGBTQ+ people.

"As a member of the LGBTQ+ community, I do not talk about that much at school or with people outside the community. Of course, I am open to conversations, but I would not bring that up randomly. I go to PRIDE outside of school, and people are from diverse racial backgrounds but relatively the same socioeconomic backgrounds. We do not talk that much about social status in our conversations as well. I think socioeconomic status is not as important as age and the level of education."

Evidence and results from both quantitative and qualitative methods report less significance of socioeconomic status in the social acceptance rate for transgender people of color. Hence, in the United States, socioeconomic status is not a crucial factor in the social acceptance rate for transgender people of color, proving that Hypothesis 2 is inaccurate.

\subsection{Hypothesis 3}

Hypothesis 3 is: People in the United States with higher education would have a higher acceptance rate towards transgender people of color. As shown in figure $7,57.1 \%$ of participants in the questionnaire view education level as a significant factor in the social acceptance rate for transgender people of color.

Some evidence bolsters the hypothesis. More than half of the participants relate higher or better education to less ignorance and more understanding about social minority groups in the short answer problems. Schools are crucial intermediaries to different worldviews, cultures, and identities. However, some answers present a lack of inclusiveness in the school's curriculum or activities for gender minorities. In figure $8,71.4 \%$ of participants have never taken any gender studies classes, and only 1 out of 42 participants have taken more than 5 classes about gender studies. $91.67 \%$ among those who have taken at least one gender studies class report the involvement of discussions around transgender people of color.
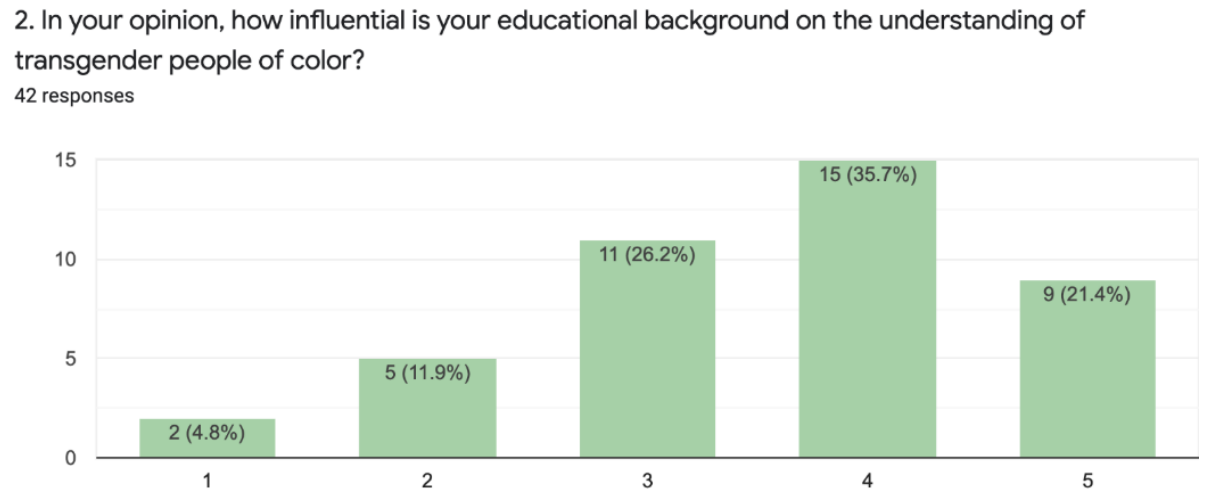

Figure 7 Participants' Answer on the Importance of Education 


\section{How many gender studies classes have you ever taken?}

42 responses

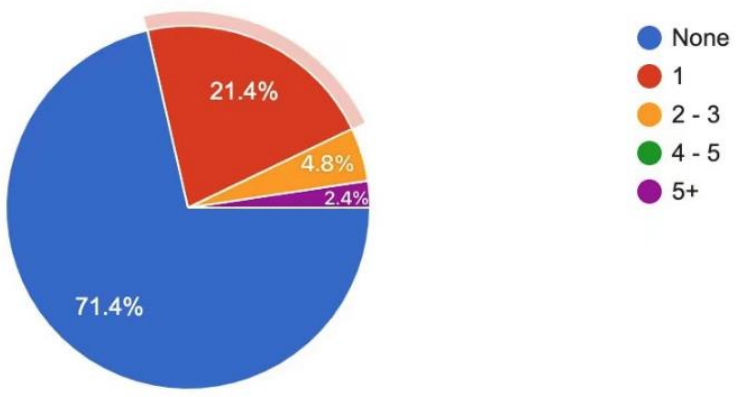

Figure 8 The Number of Gender Studies Classes Taken by Participants

In qualitative personal interviews, all participants report the importance of education in their understanding of transgender people of color. There are three major ways to build their understanding of gender and racial minorities in the education setting: Gender-neutral bathrooms, workshops around gender minorities, and discussion about current events in classrooms. One female high school student expresses her appreciation for gender-neutral bathrooms in her school.

"I was initially shocked when I saw all-gender bathrooms, but later on, it really shaped my understanding towards gender minorities. I believe gender-neutral bathrooms are a great way to embrace all people regardless of their gender identity. Bathroom issues are considered urgent since people just go there so often."

Lack of education about gender identity is brought up by several interviewees as well. A male high school teacher who holds a Ph.D. degree talks about the lack of gender conversation in his education.

"I pursued my Ph.D. degree in the music major. Regardless of the high education level, those issues [about transgender people of color] are not part of the conversation. For me, being a teacher at a high school, curiosity is the one that drives my attention or initiatives to know more about those groups. Also, teachers tend to have more discussions around gender when there is a transgender people of color in the student body."

Schools have the intention to be more inclusive towards people with different identities. Yet, a lack of education or conversation in classes among students or in the meetings among faculty members still exists.

\subsection{Extra Findings}

Other than the three hypotheses, extra findings are discovered through both the quantitative questionnaire and qualitative interviews.

\subsubsection{Relationship among age, education, and socioeconomic class}

The three factors in this study are age, education, and socioeconomic class. Instead of a parallel relationship, the three factors hold a progressive relationship. In the short answer questions in the questionnaire, more than half of the participants mention how socioeconomic class and age contribute to the educational level people usually receive, consistent with Bourdieu's theory of social reproduction [17]. During interviews, 4 out of 7 participants bring the same perspective up, considering age and socioeconomic class as two variables for the education quality or level. Education varies in decades, influencing different generations in distinct aspects and ways. Hence, a concept of "sub-factors" emerged, indicating indirect determinants to a certain phenomenon. In this case, education is the direct factor, while age and socioeconomic status are sub-factors for the social acceptance rate for transgender people of color (shown in figure 9).

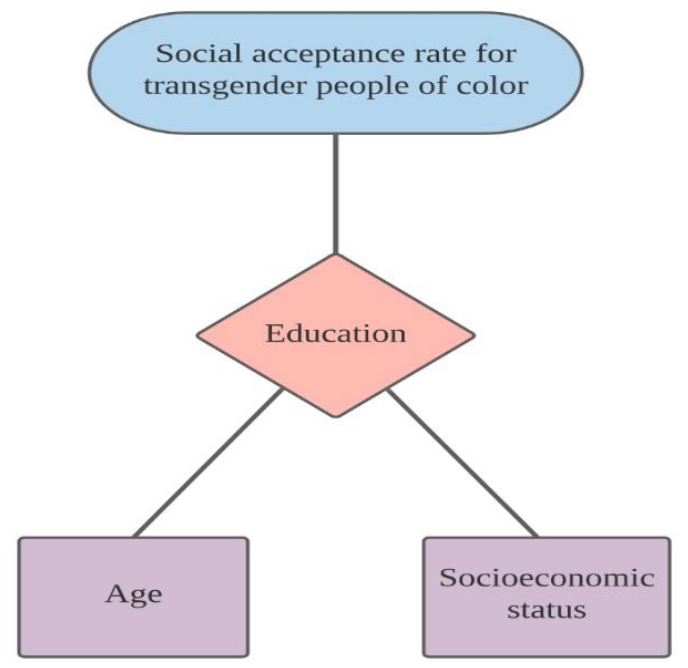

Figure 9 The Progressive Relationship Among Three Factors 


\subsubsection{Bathroom crisis}

The bathroom crisis is an important issue faced by gender minorities. In the questionnaire, some participants mentioned the benefits of gender-neutral or all-gender bathrooms. In the interviews, one transgender male mentions a private experience about the bathroom.

"I was watching a movie or something, and I went to the bathroom. Very rarely, there was a line outside the male bathroom. I went into the line, and for some reason, people using the urinal left first. I was so awkward. Like at that moment, everything came into my mind, and I just left the bathroom."

He also mentions how he usually deals with the bathroom crisis before taking medical procedures for his transition.

"I would just always go into the female bathroom because I don't want people to freak out at a teenager with a high-pitched voice."

Nonetheless, in one interview, the participant states that she cannot say if a gender-neutral bathroom is a perfect solution.

"I cannot say it. Even though it is inclusive, some people might also feel uncomfortable going into these bathrooms. And also, it may fail the concept of the gender spectrum. Instead, all the gender minorities are defined as a third gender."

Hence, the bathroom crisis is a heated topic understood by the public, while more discussions or research on the solutions is still necessary.

\subsubsection{Lack of family education}

As demonstrated in figure 10, none of the participants receive information and knowledge about transgender people of color in family education, which indicates an average lack of effort in family education about gender identity. More than $90 \%$ of the participants receive information through social media. In the interviews, there is a participant who self-identified as a transgender male. Due to his gender identity, he has regular conversations with other transgender people. However, he only receives support from his family without any family gender education in advance. The inclusive atmosphere at school assists him in exploring and find out who he is. 2 other participants in the interview mentioned the importance of starting more gender education in the family and at educational institutions to ameliorate the current situation.

\section{Where do you usually get the information and knowledge about transgender people of color? 42 responses}

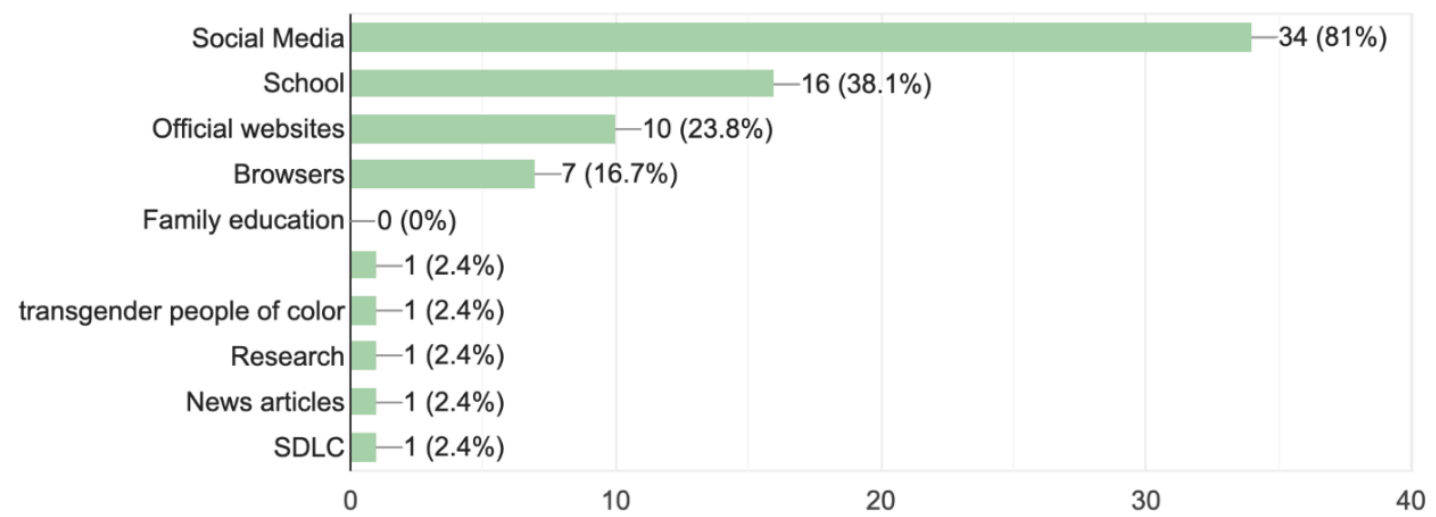

Figure 10 Ways that Participants Receive Gender Education from

\section{CONCLUSION}

This study focuses on the three factors for the social acceptance rate in the United States towards transgender people of color: Age, Education, and Socioeconomic Status. Based on the results from quantitative questionnaires and qualitative interviews, 4 major findings are discovered: 1) There is a progressive relationship among these three factors; education is the direct factor, while age and socioeconomic status are two parallel sub-factors; 2) In the scale of significance, three factors are listed in the high-low order of education, age, and socioeconomic status; 3) Bathroom crisis is a topic in consideration of transgender people of color, and it remains contradictory perspectives; 4) A lack of gender education in schools and family exists, especially in family education. This research provides a general public perspective on transgender people of color in the United States, targeting schools, educational institutions, teachers, and transgender people of color themselves. Experiencing the intersectionality between gender and race, transgender people of color are a considerably minor group in society. This paper aims to spread the knowledge of transgender people of color to the public. Some potential solutions can be concluded or derived from the answers in questionnaires and interviews. 
Schools and educational institutions can be a start to incorporate gender-neutral bathrooms and more genderrelated curriculums. Faculties and teachers should receive training on the knowledge of dealing with transgender students of color. For transgender people of color, this paper reveals the public view of themselves, encouraging them to advocate for themselves.

\section{REFERENCES}

[1] Blair-loy, M., \& Herron, M. L. (2013). The resilience of gender and gender inequality in the contemporary United States: Framed by gender: How gender inequality persists in the modern world. by Cecilia L. Ridgeway, New York, Oxford University Press, 2011. 233 pp. \$24.95 (paperback) ISBN13: 978-0-19-975578-3. Sex Roles, 68(9-10), 623-625. doi:http://dx.doi.org/10.1007/s11199-0120249-9

[2] Bloome, D., Burk, D., \& McCall, L. (2019). Economic self-reliance and gender inequality between U.S. men and women,197020100RW1S34RfeSDcfkexd09rT311RW1S34Rfe SDcfkexd09rT3. The American Journal of Sociology, 124(5),1413-1467. doi:http://dx.doi.org/10.1086/702278

[3] Styhre, A., \& Eriksson-Zetterquist, U. (2008). Thinking the multiple in gender and diversity studies: Examining the concept of intersectionality. Gender in Management, 23(8), 567-582. doi:http://dx.doi.org/10.1108/17542410810912690

[4] Taylor, B. (2019, November 24). Intersectionality 101: what is it and why is it important? Womankind Worldwide. Retrieved April 16, 2021, from https://www.womankind.org.uk/ intersectionality101-what-is-it-and-why-is-it-important/

[5] [The transgender umbrella shows different ways that people identify themselves.]. (n.d.). Media History and Development.

https://mass001.files.wordpress.com/2015/10/transgend er-umbrella.gif

[6] Helana, D. (2020). Challenging the Cisgender/Transgender binary: Nonbinary people and the transgender label. Gender \& Society, 34(3), 357-380.

doi:http://dx.doi.org/10.1177/0891243220912256

[7] Davidson, S. (2016). Gender inequality: Nonbinary transgender people in the workplace. Cogent Social Sciences, 2(1)

doi:http://dx.doi.org/10.1080/23311886.2016.1236 511
[8] Schneider, C., Cerwenka, S., Nieder, T. O., Briken, P., Cohen-kettenis, P., De Cuypere, G. Richterappelt, H. (2016). Measuring gender dysphoria: A multicenter examination and comparison of the Utrecht gender dysphoria scale and the gender Identity/Gender dysphoria questionnaire for adolescents and adults. Archives of Sexual Behavior, 45(3), 551-558. doi:http://dx.doi.org/10.1007/s10508-016-0702-x

[9] Women in the Workplace 2020. (2020, September 30). McKinsey \& Company. Retrieved April 16, 2021, from https://www.mckinsey.com/featuredinsights/diversity-and-inclusion/women-in-theworkplace

[10] Dinno, Alexis, ScD, M.P.H., M.E.M. (2017). Homicide rates of transgender individuals in the united states: 2010-2014. American Journal of Public Health, 107(9), 1441-1447. doi:http://dx.doi.org/10.2105/AJPH.2017.303878

[11] Rodriguez, A., Agardh, A., \& Benedict, O. A. (2018). Self-reported discrimination in health-care settings based on recognizability as transgender: A cross-sectional study among transgender U.S. citizens. Archives of Sexual Behavior, 47(4), 973985. doi:http://dx.doi.org/10.1007/ s10508-017-1028-Z

[12] Gonzales, G., \& CARRIE, H. (2017). Barriers to care among transgender and gender nonconforming adults. The Milbank Quarterly, 95(4), 726-748. doi:http://dx.doi.org/10.1111/1468-0009.12297

[13] Christian, R., Amy, A. M., Bui, A. G., Lee, R., Kattari, L., \& Gray, C. (2018). Measuring the health of an invisible population: Lessons from the colorado transgender health survey. Journal of General Internal Medicine, 33(10), 1654-1660. doi:http://dx.doi.org/10.1007/s11606-018-4450-6

[14] Henna, B., \& Prabal, D. (2019). Perceived stigma in health care settings and the physical and mental health of people of color in the United States. Health Equity, 3(1), 73-80. doi:http://dx.doi.org/10.1089/heq.2018.0079

[15] Katz-wise, S., Reisner, S. L., White Hughto, J., M., \& Budge, S. L. (2017). Self-reported changes in attractions and social determinants of mental health in transgender adults. Archives of Sexual Behavior, 46(5), 1425-1439. doi:http://dx.doi.org/10.1007/s10508-016-0812-5

[16] Clark, H., Babu, A. S., Wiewel, E. W., Opoku, J., \& Crepaz, N. (2017). Diagnosed HIV infection in transgender adults and adolescents: Results from the national HIV surveillance system, 2009-2014. AIDS and Behavior, 21(9), 2774-2783. doi:http://dx.doi.org/10.1007/s10461-016-1656-7

[17] Bourdieu, P., Distinction: A Social Critique of the Judgement of Taste, Cambridge: Harvest University Press, 1979. 